\title{
Rara and grammatical theory
}

\author{
Jan Rijkhoff
}

\section{Introduction}

This paper shows that rare typological features have lead to a better understanding of parallels between the structure of the noun phrase and the structure of the clause. The paper is organized as follows. Section 2 ('Preliminaries') deals with the relevance of typological data for grammatical theory and briefly discusses the only sampling method that explicitly aims at including rara and rarissima. Section 3 demonstrates that the further development of a symmetrical model of the structure of the noun phrase and the clause depended on the existence of two rare grammatical phenomena. The more general point this paper wants to make is that rara and rarissima can play a crucial role in the validation of theoretical claims and serve as a heuristics for an extension of grammatical theory.

\section{Preliminaries}

Rare linguistic features should play in important role in grammatical theory, if only because a theory that can account for both common and unusual grammatical phenomena is superior to a theory that can only handle common linguistic properties. As was already noted by Perkins (1988: 367), “[... ] exceptional types test the theory". In reality, however, very few grammatical theories can be said to strive for typological adequacy (Butler 2003: 200-201, 246). Some notable exceptions are Dik's Functional Grammar (Dik 1997) and its successor Functional Discourse Grammar (Hengeveld and Mackenzie 2008), which systematically take into account data from a wide range of typologically, genetically and geographically different languages. These data are often collected using a sampling procedure that is designed to produce variety samples, i. e. samples that are representative for the linguistic diversity across the globe. This sampling method produces samples in which the genetic (historic) distance between languages is always maximal and in which languages are distributed proportionally across families and subfami- 
lies on the basis of linguistic variety rather than quantitative considerations (such as the number of languages that belong to a certain family or subfamily). Consequently, the chance of attesting rara or rarissima is significantly higher in a variety sample than in a probability sample or a random sample (Rijkhoff et al. 1993; Rijkhoff and Bakker 1998).

For grammatical theories that strive for typological adequacy, frequency of occurrence is relatively unimportant. Since a general theory of grammar should be able to deal with facts from any natural human language, all grammatical properties are relevant. What counts most is the fact that some property (a sound, a meaning, a form, a construction, etc.) is attested in one of the world's languages, not so much the number of languages that happen to share some property, as this may be due to a historical accident.

Since variety sampling forces the linguist to systematically cover all the language families in a top-down fashion, taking into consideration facts from languages from increasingly more subfamilies as the size of the sample grows, a variety sample may also be used to demonstrate that some grammatical phenomenon is actually less common than is generally assumed. For example, a variety sample of 52 languages that is representative of the world's languages contained only one clear example of a language that has a proper agreement relation between the subject and the verb: Dutch. In this language, the verb agrees in number/person with the nominal or pronominal subject NP (Rijkhoff 1992: 30-31, Rijkhoff 2004: 246-247).

(1) Dutch: agreement

a. Ik loop $\quad[* \emptyset$ loop]
I walk

'I am walking.'

b. Je/Hij/Zij/Het kind loop-t you.SG/he/she/the child walk-PRES.2/3SG

[*ø loopt]

'You are / He / She / The child is walking.'

c. We/Jullie loop-en (spelled: lopen) [*Ølopen] we/you.PL walk-PRES.PL

'We / You are walking.'

d. Ze/De meisje-s loop-en (spelled: lopen) [*Ølopen]

They/the girl-PL walk-PRES.PL

They/ The girls are walking. ",

Notice that the subject NP or pronoun is compulsory in Dutch and that the agreement marker on the verb is not a referential element. The grammat- 
ical AGREEMENT relation attested in Dutch is to be distinguished from the CROSS-REFERENCING relation, where the person marker on the verb does have referring potential (as in Latin cantamus 'we sing') and the free subject NP or pronoun is normally only expressed under special circumstances, such as emphasis (Latin nos cantamus 'WE sing'; Dik 1997: 154; Siewierska 2004: 121). The latter phenomenon is often called 'Pro-drop', which is a misnomer of course, as the free subject pronoun is added rather than dropped.

In other words, contrary to what is commonly assumed, grammatical Subject-Verb agreement as attested in Dutch, German and certain other Germanic languages (not e. g. Danish), is very marked from a cross-linguistic perspective. In a variety sample of 272 languages, it only occurred in one other language besides Dutch: Vanimo, a New Guinea language of the Sko family (Siewierska 1999: 238-239; see also de Vogelaer and van der Auwera, (2010)). Next we will discuss the crucial role rara have played in the further development of a theory about parallels between the structure of noun phrases and clauses.

\section{The importance of rara for grammatical theory}

A general theory of grammar cannot be developed without being exposed to linguistic facts from a wide variety of (genetically, geographically, typologically) different languages, and, conversely, empirical research is best guided by theoretical questions (Rijkhoff 2002). ${ }^{1}$

The main goal of this paper is to show how two rare grammatical phenomena made it possible to propose an improved, unified analysis of the noun phrase (NP) and the clause.

Both formal and functional linguists have developed models in which clauses and NPs are at least partly analyzed in a similar fashion. Whereas formal approaches to grammar have concentrated on similarities between the underlying syntactic structure of the NP and the clause (e. g. Jackendoff 1977; Abney 1987), theories such as Functional (Discourse) Grammar have investigated parallels between functional, meaning-based representations of the NP and the clause (Rijkhoff 1990, 1992, 2004, 2008b). Thus, in the functional approach to grammar, linguistic forms and constructions are also characterized in terms of labels that capture the functional contribution they make to a linguistic expression (Rijkhoff 2008b, 2009). Furthermore, the design of 'structural-functional theories' (Butler 2003) like Role and Reference Grammar and Functional (Discourse) Grammar is based on a multilayered con- 


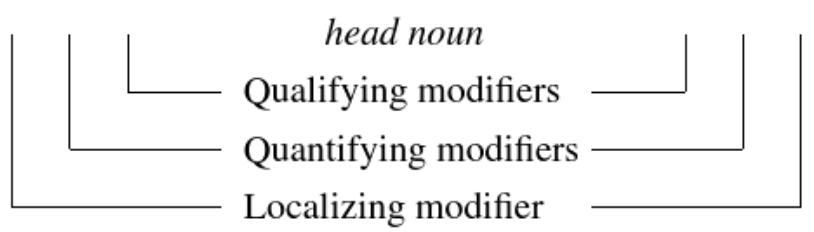

Figure 1. Layers of modification in the NP (Rijkhoff 1992)

ception of linguistic structure, i. e. a hierarchical type of meaning-based linguistic structuring, where a higher layer (in terms of scope) is seen as being superimposed on other, lower, layers (Butler and Taverniers 2008: 680-681).

The first layered model of the noun phrase was proposed in Rijkhoff (1988), shortly after Hengeveld $(1987,1988)$ had put forward a layered analysis of clausal structures. Initially only three layers of modification were recognized in the NP: the innermost layer for qualifying modifiers (Quality Layer), the outermost layer for localizing modifiers (Location Layer) and in between a Quantity Layer to accommodate quantifying modifiers (Figure 1; recall that this meaning-based representation reflects differences in scope rather than syntactic relations).

QUALIFYING MODIFIERS have scope over the head constituent and specify more or less inherent properties (qualities or attributes) of the referent of the noun phrase, such as size (a small house, telescopes of enormous size), value or quality (an expensive suit, wine of an incredible richness), age (a young child, youths under age 15), or colour (red curtains, a Jovian moon of incredible redness). These examples also show that the same function (here QUALIFYING MODIFIER) can be performed by members that belong to different form classes, such as adjectives ( $\mathrm{big}$ ) or prepositional phrases (of enormous size). Languages without a distinct class of adjectives, such as Eastern Ojibwa (Algonquian; USA and Canada), often employ relative clauses headed by a stative verb instead.

(2) Eastern Ojibwa (Dryer 2008)

nini e-gnoozi-d

man REL.PX-tall-3SG

'a tall man'

QUANTIFYING MODIFIERS have scope over the quality layer and the head constituent and indicate number distinctions and the cardinality of the referent of the NP ('two big car-s'). Some languages employ lexical modifiers for 
this purpose. For example, Krongo (Kordofanian) uses verbal forms to indicate the cardinality of a referent.

(3) Krongo (Reh 1985: 252)

nóo-còorì nk-óotòonò

PL-house CN.PL-IMPF:be_three

'three houses'

LOCALIZING MODIFIERS have the widest scope, specifying properties concerning the location of the referent in physical or cognitive space, as in 'those two old houses', 'the house on that hill', but also e. g. 'my house' (on the relation between location and possession, see Rijkhoff 2004: 173212).

It was already argued in Rijkhoff (1988) that NPs and clauses (or rather "predications") could be analyzed in a similar fashion. The fact that the layers are organized hierarchically, meaning that modifiers of an outer layer have scope over modifiers of an inner layer, is indicated schematically and in a theory-neutral fashion in Figure 2 on the following page (a detailed, formal representation can be found in Rijkhoff 2008b). By convention, grammatical (i. e. non-lexical) categories like Definiteness, Number, Tense or Aspect are represented on the left side, i. e. before the head constituent (verb or noun), whereas phrasal or lexical modifiers like adjectives, genitives, adverbs or adpositional phrases (which involve content words) are specified after the head.

Since there is often no one-to-one relationship between the form and the function of a modifier (see above), only some typical forms or constructions for the three modifier categories are specified in Figure 2. For example, adnominal prepositional phrases can be employed as qualifying (children under age 6) or localizing modifiers (the cat under the table). In Figure 3 on the next page, the modifiers in 'those three black dogs in the garden' appear in the appropriate slots of the various layers.

Subsequently it became apparent that the layered structure of the NP is more articulate and that at least two more layers of modification should be added, one for discourse-referential modifiers (Section 3.1) and another to accommodate classifying modifiers (Section 3.2). It was not immediately clear, however, what elements could qualify as a classifying or discourse-referential modifier at the level of the clause. It was at this point that certain rare linguistic features played an essential role in the further development of a theory about parallels between meaning-based representations of NP and clause structure. 

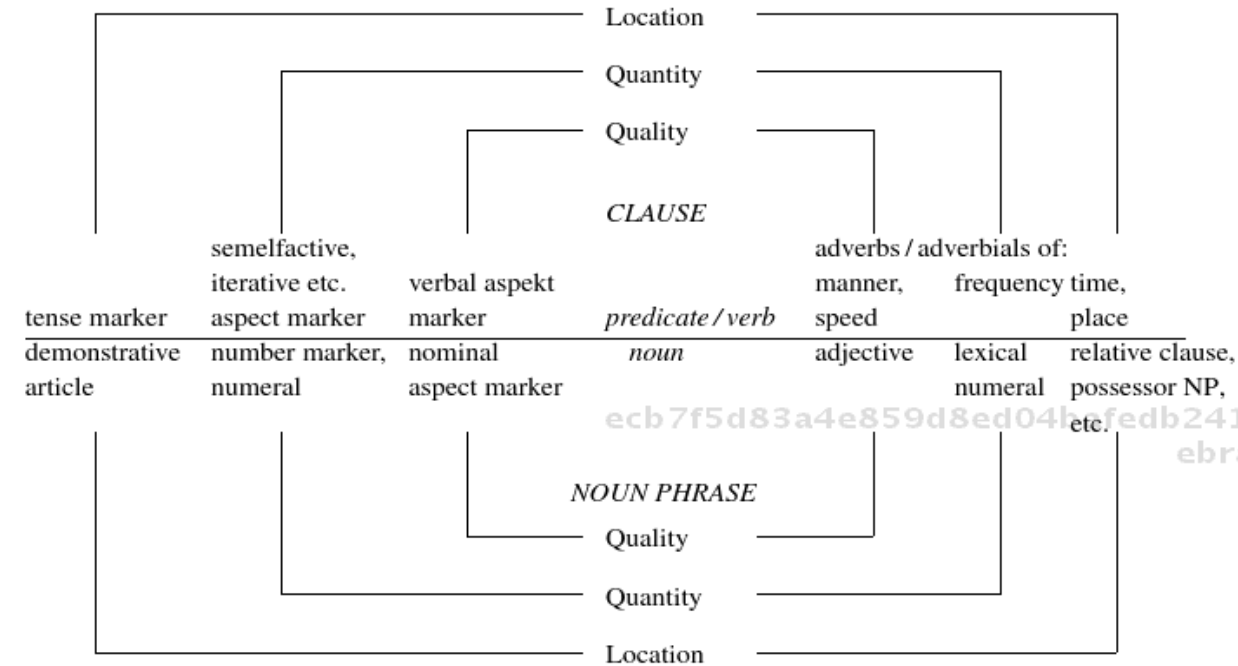

grammatical modifiers (NP)

lexical modifiers $(N P)$

Figure 2. Symmetry in the underlying structure of the clause and the NP as proposed in Rijkhoff 1992 (see Figure 6 for the current version)

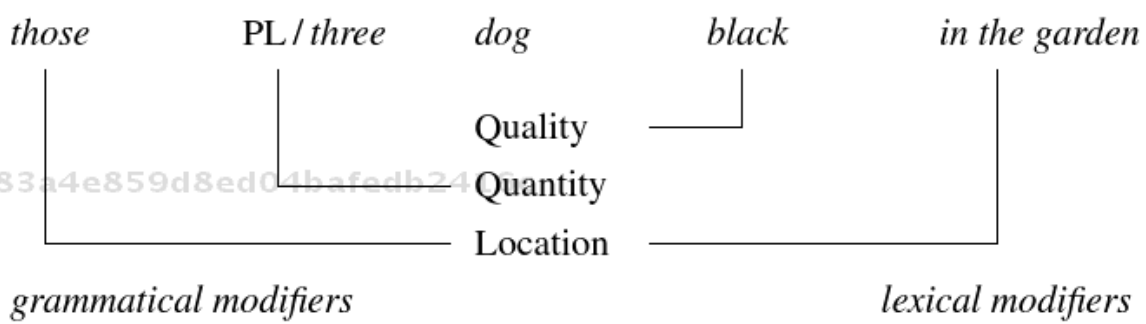

Figure 3. Modifiers in a layered model of NP: a simplified representation of 'those three black dogs in the garden'

\subsection{Discourse-referential modifiers in the clause and in the NP}

In the first version of the layered model of the NP, definite articles were regarded as LOCALIZING MODIFIERS (together with e. g. adnominal demonstratives), because they indicate 'weak deixis' (Anderson and Keenan 1985: 
261-262). There are some important differences, however, between definite articles and other localizing modifiers, such as adnominal demonstratives. For example, whereas adnominal demonstratives basically specify a spatial property of the referent (its spatial location relative to a reference point), definite articles indicate that the speaker assumes the referent of the NP to be identifiable for the addressee in the shared world of discourse (a mental construct). In other words, the difference between demonstratives and definite articles can be compared to the difference between semantics and pragmatics (cf. Levinson 2000). Whereas demonstratives are concerned with a static, descriptive semantic property of the referent of the NP ("language as carrier of content"), definite and indefinite articles relate to a more dynamic, pragmatic property of the referent: its referential or existential status in the world of discourse ("language as exchange", "language as communicational process"). By using a definite NP, the speaker signals that (s)he assumes that the addressee is familiar with the referent of the NP or that the addressee will be able to identify the referent in conversational space. Conversely, by using an indefinite NP, the speaker indicates that the addressee is not expected to identify the referent. In the literature, the distinction between the coding of a static descriptive meaning and the coding of a dynamic inter-subjective meaning goes back to Bühler (1999 [1934]) and has more recently been discussed in terms of the notions 'ideational' vs. 'interpersonal' (Halliday 2004: 61) or 'representational' vs. 'interpersonal' (Hengeveld and Mackenzie 2008) and can also be paraphrased as the coding of content-related meaning vs. the coding of speaker/hearer-related meaning (Butler 2003: 111; Butler and Taverniers 2008: 681).

Since adnominal demonstratives and markers of (in)definiteness belong to different functional modifier categories, it seemed appropriate to assign (in)definite articles and other modifiers that indicate interpersonal or discourse properties of the referent their own place in a layered model of the noun phrase. Thus a new layer was established to accommodate so-called DISCOURSE-REFERENTIAL MODIFIERS. After markers of (in)definiteness were re-categorized as grammatical instances of Discourse-Referential modifiers, it was not very difficult to find lexical instances of this new category: modifiers such as same and other also provide the addressee with information about the referent as a discourse entity. The modifier (the) same tells the addressee (s)he should find a particular referent that was mentioned a little earlier in the conversation. In the case of (the) other, the addressee is instructed to identify the second member of a referent set that was introduced 
before. By using the indefinite counterpart another (as in: I gave her another book) the speaker instructs the addressee to construe a new token of a certain kind of entity (book) that already exists as a distinct referent in the discourse world and was mentioned not long before (Rijkhoff 2008c: 798-800).

If it is correct that all the layers of modification that we find in the NP are also relevant for the analysis of clausal structures, then one would expect there to exist discourse-referential modifiers in the clause as well. ${ }^{2}$ The occurrence of a rare phenomenon attested in Jacaltec, a Mayan language spoken in Guatemala (see also Martin 1998 and Vidal and Klein 1998), was of crucial importance in the search for clausal counterparts of markers of (in)definiteness and modifiers like same and other. Jacaltec employs the same morpheme to express NONSPECIFIC-INDEFINITENESS in the NP and IRREALIS in the clause (variation between $/ \mathrm{oj} /$ and $/ \mathrm{uj} /$ is due to vowel harmony):

(4) Jacaltec (Craig 1977: 93)

a. X-Ø-'oc hebix say- $a$ ' hun-uj munlabel

ASP-ABS.3-start PL woman look_for-FUT a-OJ pot

'The women started looking for a pot.' [nonspecific reference]

b. Way-oj ab naj

sleep-OJ EXH CLF/he

'Would that he slept!' [irrealis: exhortative mood]

The reason that speakers of Jacaltec can use /OJ/ both in the NP and in the clause is, presumably, that both Nonspecific-indefiniteness and Irrealis signal to the addressee that the (spatial or temporal) entity in question is not 'anchored' or 'grounded' in the world of discourse at the moment of speaking, i. e. it does not exist (yet) as an identifiable object or a real event at a certain time or place in the shared word of discourse of Speaker and Addressee(s). The fact that the clausal category Irrealis, just like Nonspecific-indefiniteness in the NP, relates to the existential status of an entity in the world of discourse is a strong indication that irrealis markers should be regarded as DiscourseReferential modifiers at the level of the clause.

More evidence for this analysis is provided by another rare grammatical phenomenon. In Fongbe (a Kwa language spoken mainly in Benin) the same morpheme is used to express DEFINITENESS in the NP and REALIS in the clause. To put it differently, speakers of Fongbe use the same marker in NPs and in clauses to indicate that a thing or event is grounded in the world of discourse, i. e. that it occupies a specific spatio-temporal region in the world of discourse at the moment of speaking (Rijkhoff 1990; Rijkhoff and Seibt 
2005). In these examples from Fongbe the element in question is glossed as DET (determiner)

(5) Fongbe (Lefebvre 1998: 94, 99; cf. also Lefebvre and Brousseau 2002)

a. $N$ dú àsón ó

I eat crab DET

'I ate the crab.' (i.e. the crab in question / that we know of)

b. Jan wá ó

John arrive DET

'Actually, John arrived.'

These data from Jacaltec and Fongbe were essential in demonstrating that a typologically adequate representation of NP and clause structure needs to provide a separate slot for DISCOURSE-REFERENTIAL MODIFIERS, which relate to the existential status of the referent (thing or event) in the world of discourse at the moment of speaking (Figure 4$):^{3}$

(a) Definite and realis indicate that the thing or event being referred to by the speaker is grounded (occupies a certain spatio-temporal region) in the world of discourse, and

(b) Nonspecific-indefinite and irrealis indicate that the thing or event being referred to by the speaker is not grounded (does not occupy a certain spatio-temporal region) in the world of discourse.

\begin{tabular}{clll}
\hline Noun Phrase (thing) & $\begin{array}{l}\text { OCCURRENCE IN WORLD } \\
\text { OF DISCOURSE AT MO- } \\
\text { MENT OF SPEAKING }\end{array}$ & Clause (event) \\
\cline { 2 - 4 } ebrafinite Reference & $\begin{array}{l}\text { GROUNDED IN DIS- } \\
\text { COURSE WORLD }\end{array}$ & Realis Mood \\
\hline $\begin{array}{c}\text { Nonspecific-indefinite } \\
\text { Reference }\end{array}$ & $\begin{array}{l}\text { NOT GROUNDED IN DIS- } \\
\text { COURSE WORLD (YET) }\end{array}$ & Irrealis Mood \\
\hline
\end{tabular}

Figure 4. Symmetry between Definite/Realis and Nonspecific-indefinite / Irrealis.

Once (ir)realis markers were identified as the clausal counterparts of the grammatical discourse-referential modifiers in the NP, it was obvious that adverbs like 'actually' or 'really' should be analyzed as lexical manifestations of discourse-referential modifiers in the clause. These adverbs are concerned 
with the existential status of events as discourse entities in conversational space, as they indicate whether or not the speaker regards the event in question is grounded or real (Rijkhoff 2008b: 68-74). The hierarchical position of Discourse-Referential modifiers in the layered model (now the outermost layer) can be seen in Figure 5 (see Rijkhoff 2008b, 2008c for details about scopal and other properties of discourse-referential modifiers):

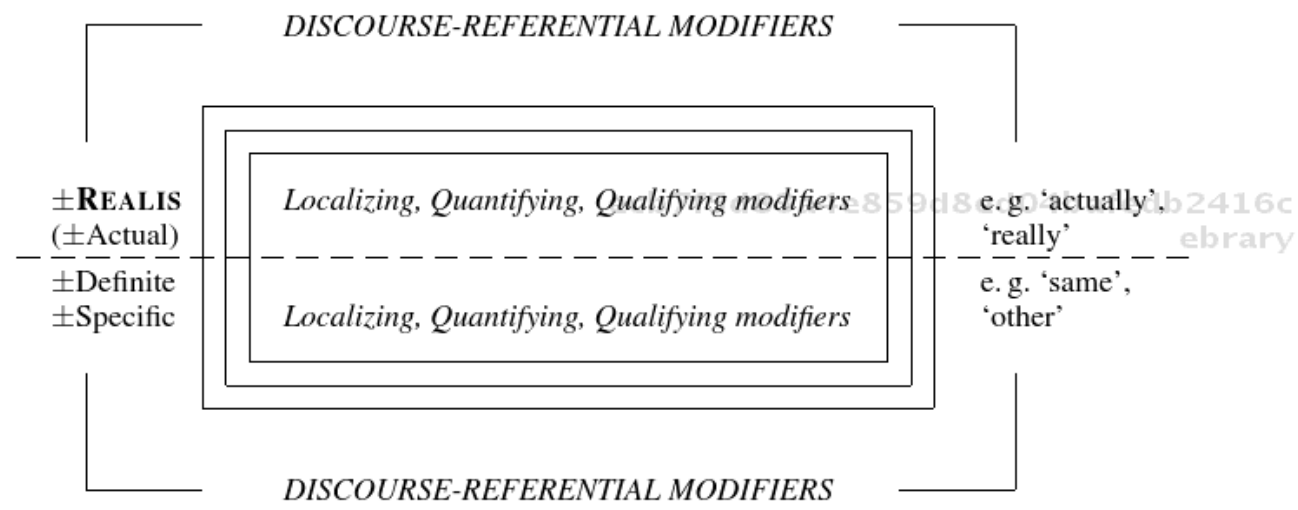

Figure 5. Discourse-referential modifiers in a layered representation of the underlying structure of the clause and the NP

\subsection{Classifying modifiers in the clause and in the NP}

Several linguists have discussed the fact that certain modifiers in the NP classify the entity as denoted by the head noun into a system of smaller sets (Quirk et al. 1985; Halliday 2004), as in these examples: electric train, divorce lawyer, departmental meeting. In languages that have them, classifying adjectives (typically noun-derived or 'relational' adjectives) differ from other adjectives in several ways. For instance, they immediately precede or follow the head noun and they do not admit intensifiers, comparison, or predicative position:

(6) [adjacency]

a. the popular corporate lawyer vs. *the $\begin{gathered}\text { corporate } \\ \text { lawyer }\end{gathered}$ popular


(7) [intensifier]
a. the electric train
vs. * the very electric train
b. the long train
vs. the very long train

(8) [comparison]
a. a medical examination
vs. *a more medical examination
b. an expensive book
vs. a more expensive book

(9) [predicate]
a. the presidential election
vs. *the election is presidential
b. the white table
vs. the table is white

The search for lexical manifestations of classifying modifiers in the clause did not yield any clear results until we became aware of the unusual grammatical phenomenon of 'stripped nouns' (Mithun 1984; Miner 1986, 1989; Gerdts 1998; Caballero et al. 2008). The fact that some languages have a distinct category of free lexical modifiers at the level of the clause that subclassify an event made it possible to add another shared layer of modification to the symmetrical representation of NP/clause structure.

Superficially, stripped nouns are similar to incorporated nouns but there is an important difference. Whereas an incorporated element is part of another word, a stripped noun, which must appear next to the verb it modifies, is a separate word according to phonological criteria such as stress placement. Thus, in Kusaiean adverbs can appear between verb and object (10), but not between verb and stripped noun (11). Notice that in these examples a distinction is made between sharpening in general (10) and a particular kind of sharpening, namely knife-sharpening (11).

(10) Kusaiean (Gerdts 1998: 94; original example in Lee 1975)

Sahel twem upac mitmit sac

Sah he sharpen diligently knife the

'Sah is sharpening the knife diligently'

With a stripped noun:

(11) Sah el twetwe mitmit upac

Sah he sharpen knife diligently

'Sah is diligently knife-sharpening'

Adding a separate layer of modification to accommodate CLASSIFYING MODIFIERS resulted in the symmetrical analysis of NP and clause structure 


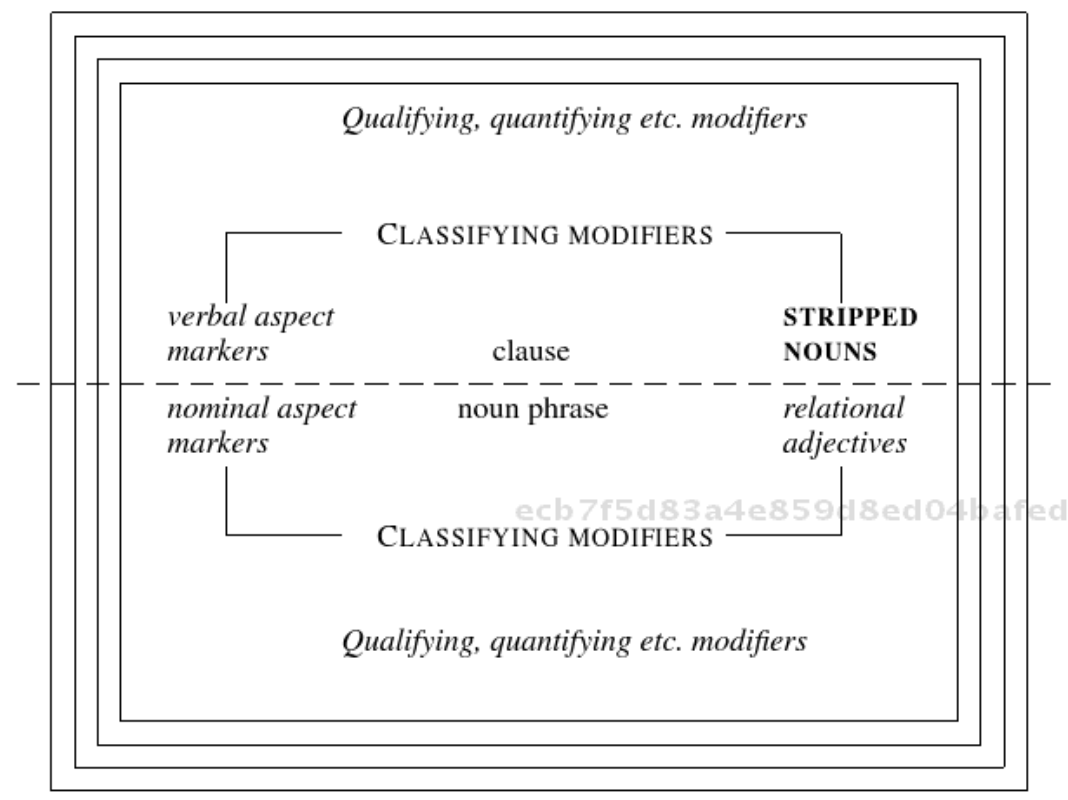

Figure 6. ClAsSifying MODIFIERS in a layered analysis of symmetrical NP and clause structure.

shown in Figure 6 (recall that scopal relations among modifier categories are discussed in Rijkhoff 2008b, 2008c). Notice that nominal and verbal aspect markers, originally treated as QUALIFYING MODIFIERS (Rijkhoff 2004: 224), are now analyzed as CLASSIFYING MODIFIERS (this is explained in Rijkhoff 2008b: 84-86).

\section{A five-layered model of the clause and the NP}

Adding the two new layers discussed in Sections 3.1 and 3.2 to the original proposal (Figure 2 on page 228) gives the following five-layered symmetrical $\mathrm{NP} /$ clause structure.

As can be seen in Figure 7 on the facing page, there is now a certain asymmetry in the distribution of grammatical and lexical modifiers in that grammatical manifestations of QUALIFYING MODIFIERS are no longer deemed to exist (this is explained in Rijkhoff 2008a: 85-86; see also Rijkhoff 2008b: 794). 


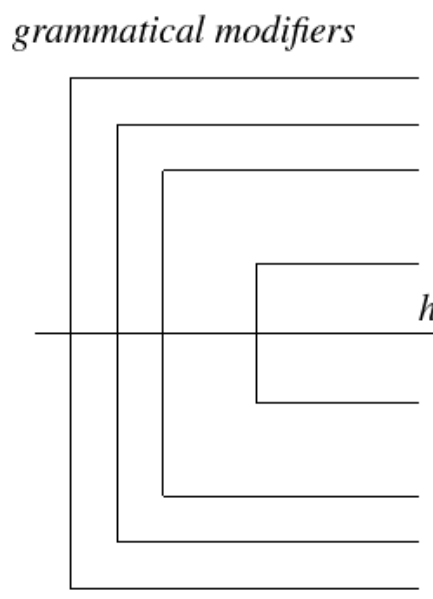

grammatical modifiers
CLAUSE lexical modifiers

\section{Discourse-referential}

3. Location

2. Quantity

1. Quality

0. Kind

head: verb/main predicate

head (noun)

\section{Kind}

1. Quality

2. Quantity

3. Location

4. Discourse-referential NOUN PHRASE

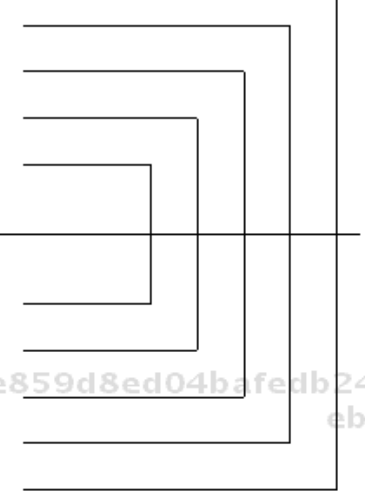

lexical modifiers

Figure 7. Parallels in the layered structure of the NPs and the clause

\title{
5 Conclusion
}

In this paper I have tried to highlight the importance of rara for grammatical theory by showing how hypotheses about certain parallels between the structure of NPs and clauses could only be confirmed on the basis of two uncommon linguistic phenomena: (i) stripped nouns and (ii) isomorphic markers of Definiteness / Realis (Fongbe) and Indefiniteness / Irrealis (Jacaltec). Thus, it would be wrong to treat rara as curiosities that are only marginally interesting for the study of language. Rara and rarissima are at least as important for the development of a general, typologically adequate theory of grammar as the more commonly attested linguistic phenomena.

\begin{abstract}
Abbreviations
$1 / 2 / 3=1 \mathrm{st} / 2 \mathrm{nd} / 3 \mathrm{rd}$ person; $\mathrm{A}=$ adjective; $\mathrm{ABS}=$ absolutive; $\mathrm{ASP}=$ aspect $\mathrm{CL}=$ class $; \mathrm{CLF}=$ classifier $\mathrm{COM}=$ comitative $; \mathrm{DET}=$ determiner DV = diversity value; $\mathrm{EXH}=$ exhortative; $\mathrm{N}=$ noun $; \mathrm{NP}=$ noun phrase $; \mathrm{M}=$ masculine PAST = past; PERF = perfective; $\mathrm{PL}=$ plural PRES = present REL.PX = relativizing prefix $; \mathrm{S}=$ subject; $\mathrm{SG}=$ singular; $\mathrm{V}$ =verb
\end{abstract}




\title{
Notes
}

1. The claim that empirical research needs some kind of theoretical perspective is not new, of course, as can be seen, for example, in this quotation from a letter by Charles Darwin to Henry Fawcett (10 September 1861):

\begin{abstract}
"About thirty years ago there was much talk that geologists ought to observe and not theorise; $[\ldots]$ at this rate a man might as well go into a gravel-pit and count the pebbles and describe the colours. How odd it is that anyone should not see that all observations must be for or against some view if it is to be of any service."
\end{abstract}

2. Clauses have at least two additional layers of modification: one for modal and another for illocutionary distinctions (Rijkhoff 2008a: 101; Rijkhoff 2008b: 812).

3. Referents of definite NPs can be grounded (or presumed grounded) for various reasons, whereas referents of real events become grounded at the moment of speaking. These and other aspects of the anti-symmetrical relation between (in)definiteness and (ir)realis, in which Definite aligns with Irrealis and Specific-Indefinite with Realis, are discussed in Rijkhoff and Seibt (2005) and Rijkhoff (2008b).

\section{References}

Abney, Stephen P.

1987 The English noun phrase in its sentential aspect. Doctoral dissertation, Massachusetts Institute of Technology.

Anderson, Stephen R., and Edward L. Keenan

1985 Deixis. In Language Typology and Syntactic Description. Volume III: Grammatical Categories and the Lexicon, Timothy Shopen (ed.), 259-308. Cambridge: Cambridge University Press.

Bühler, Karl

[1934] 1999 Sprachtheorie: Die Darstellungsfunktion der Sprache. Reprint. Stuttgart: UTB. [Original edition: Jena: Fischer, 1934.]

Butler, Christopher S.

2003 Structure and Function: A Guide to Three Major Structural-Functional Theories. Part 1: Approaches to the Simplex Clause (= Studies in Language Companion Series; 63). Amsterdam/Philadelphia: Benjamins.

Butler, Christopher S., and Miriam Taverniers

2008 Introduction [to a special issue on 'layering' in grammatical theory]. Linguistics 46.4: 679-687.

Caballero, Gabriela, Michael J. Houser, Nicole Marcus, Teresa Mcfarland, Anne Pycha, Maziar Toosarvandani, and Johanna Nichols

2008 Nonsyntactic ordering effects in noun incorporation. Linguistic Typology 12.3: $383-421$.

Craig, Colette Grinevald

1977 The Structure of Jacaltec. Austin: University of Texas Press. 
de Vogelaer, Gunther, and Johan van der Auwera

2010 When typological rara become productive: the extension of grammatical agreement in Dutch dialects. In Rara \& Rarissima: Documenting the fringes of linguistic diversity, Jan Wohlgemuth and Michael Cysouw (eds.), 47-73. (= Empirical Approaches to Language Typology; 46). Berlin/New York: Mouton de Gruyter.

Dik, Simon C.

1997 The Theory of Functional Grammar (2nd revised edition edited by Kees Hengeveld). Part 1: The Structure of the Clause. Part 2: Complex and Derived Constructions. Berlin / New York: Mouton de Gruyter.

Dryer, Matthew S.

2008 Order of adjective and noun. (Chapter 87) In The World Atlas of Language Structures Online, Martin Haspelmath, Matthew S. Dryer, David Gil and Bernard Comrie (eds.). München: Max Planck Digital Library. ed 04 b a fed b $2416 \mathrm{c}$ http://wals.info/feature/87 (31 December 2008).

Gerdts, Donna B.

1998 Incorporation. In The Handbook of Morphology, Andrew Spencer and Arnold M. Zwicky (eds.), 84-100. Oxford: Blackwell.

Halliday, Michael Alexander Kirkwood

2004 An Introduction to Functional Grammar. 3rd edition, revised by Christian M. I. M. Matthiessen. London: Arnold.

Hengeveld, Kees

1987 Clause structure and modality in Functional Grammar. In Ins and Outs of the Predication, Johan van der Auwera and Louis Goossens (eds.), 53-66. (= Functional Grammar Series; 6). Dordrecht: Foris.

Hengeveld, Kees

1988 Layers and operators. (= Working Papers in Functional Grammar; 27). Department of Linguistics, University of Amsterdam.

Hengeveld, Kees and J. Lachlan Mackenzie

$2008 \quad$ Functional Discourse Grammar: a typologically based theory of language ecb 7 f 5 d 83 a 4 e8 5 structure. Oxford: Oxford University Press.

Jackendoff, Ray S.

$1977 \quad X$-bar Syntax. Cambridge, MA: MIT Press.

Lee, $\mathrm{K}$.

1975 Kuseian Reference Grammar. Honolulu: University Press of Hawaii.

Lefebvre, Claire

1998 Multifunctionality and variation among grammars: the case of the determiner in Haitian and in Fongbe. Journal of Pidgin and Creole Languages 13.1: 93150.

Lefebvre, Claire and Anne-Marie Brousseau

2002 A Grammar of Fongbe (= Mouton Grammar Library; 25). Berlin / New York: Mouton de Gruyter.

Levinson, Stephen C.

2000 Presumptive Meanings: the theory of generalized conversational implicature.

Cambridge, MA: MIT Press. 
Martin, Laura

1998 Irrealis constructions in Mocho (Mayan). Anthropological Linguistics 40.2: 198-213.

Miner, Kenneth L.

1986 Noun stripping and loose incorporation in Zuni. International Journal of American Linguistics 52.3: 242-254.

Miner, Kenneth L.

1989 A note on noun stripping. International Journal of American Linguistics 55: $476-477$.

Mithun, Marianne

1984 The evolution of noun incorporation. Language 60.4: 847-894.

Perkins, Revere D.

1988 The covariation of culture and grammar. In Studies in Syntactic Typology, Michael Hammond, Edith A. Moravcsik, and Jessica R. Wirth (eds.), 359-378. (= Typological Studies in Languages; 17). Amsterdam/Philadelphia: Benjamins.

Quirk, Randolph, Sidney Greenbaum, Geoffrey Leech, and Jan Svartvik 1985 A Comprehensive Grammar of the English Language. London: Longman.

Reh, Mechthild

1985 Die Krongo-Sprache (Nìnò Mó-dì) - Beschreibung, Texte, Wörterverzeichnis. Berlin: Reimer.

Rijkhoff, Jan

1988 A typology of operators: toward a unified analysis of terms and predications.

Working Papers in Functional Grammar 29. Department of Linguistics, University of Amsterdam.

Rijkhoff, Jan 1990

Toward a unified analysis of terms and predications. In Layers and Levels of Representation in Language Theory: a functional view, Jan Nuyts, A. Machtelt Bolkestein, and Co Vet (eds.), 165-191. Amsterdam/Philadelphia: Benjamins.

Rijkhoff, Jan 1992

Rijkhoff, Jan 2002

Rijkhoff, Jan 2004

Rijkhoff, Jan 2008a
The noun phrase: a typological study of its form and structure. Doctoral dissertation, University of Amsterdam.

On the interaction of Linguistic Typology and Functional Grammar. Functions of Language 9.2: 209-237.

The Noun Phrase. Oxford: Oxford University Press. [expanded paperback edition of 2002 hardback publication].

Synchronic and diachronic evidence for parallels between noun phrases and sentences. In Interdependence of Diachronic and Synchronic Analyses, Folke Josephson and Ingmar Söhrman (eds.), 13-42. (= Studies in Language Companion Series; 103). Amsterdam / Philadelphia: Benjamins. 
Rijkhoff, Jan

2008b Layers, levels and contexts in Functional Discourse Grammar. In The Noun Phrase in Functional Discourse Grammar, Daniel García Velasco and Jan Rijkhoff (eds.), 63-115. (= Trends in Linguistics. Studies and Monographs; 195). Berlin/New York: Mouton de Gruyter.

Rijkhoff, Jan

2008c Descriptive and discourse-referential modifiers in a layered model of the noun phrase. Linguistics 46.4: 789-829.

Rijkhoff, Jan 2009

On the co-variation between form and function of adnominal possessive modifiers in Dutch and English. In The Expression of Possession, William B. McGregor (ed.), 51-106. (= The Expression of Cognitive Categories; 2). Berlin/New York: Mouton de Gruyter.

Rijkhoff, Jan, Dik Bakker, Kees Hengeveld and Peter Kahrel 1993 A method of language sampling. Studies in Language 17.1: 169-203.

Rijkhoff, Jan, and Dik Bakker

$1998 \quad$ Language sampling. Linguistic Typology 2.3: 263-314.

Rijkhoff, Jan, and Johanna Seibt

2005 Mood, definiteness and specificity: a linguistic and a philosophical account of their similarities and differences. Sprog - Tidsskrift for Sprogforskning 3.2:

85-132. http://ojs.statsbiblioteket.dk/index.php/tfs/article/view/89/74

Ruhlen, Merritt

1987 A guide to the world's languages. Vol. 1: Classification. London: Arnold.

Ruhlen, Merritt

$1991 \quad$ A guide to the world's languages. Vol. 1: Classification (with a postscript on recent developments). London: Arnold.

Siewierska, Anna

1999 From anaphoric pronoun to grammatical agreement marker: why objects don't make it. Folia Linguistica 33: 225-251.

Siewierska, Anna

2004 Person. Cambridge: Cambridge University Press.

Vidal, Alejandra and Harriet P. Manelis Klein

1998 Irrealis in Pilagá and Toba? Syntactic versus pragmatic coding. Anthropological Linguistics 40.2: 175-197. 
. Empirical Approaches to Language Typology : Rethinking Universals : How Rarities affect Linguistic Theory. : Walter de Gruyter, . p 250

http://site.ebrary.com/id/10381224?ppg=250

Copyright (@) Walter de Gruyter. . All rights reserved.

May not be reproduced in any form without permission from the publisher, except fair uses permitted under U.S. or applicable copyright law. 